\title{
Curcumin inhibits cobalt chloride-induced epithelial-to-mesenchymal transition associated with interference with TGF- $\beta /$ Smad signaling in hepatocytes
}

\author{
Desong Kong ${ }^{1,6}$, Feng Zhang ${ }^{2,3,6}$, Jiangjuan Shao ${ }^{4}$, Li Wu², Xiaoping Zhang ${ }^{5}$, Li Chen², Yin Lu ${ }^{2,3}$ and \\ Shizhong Zheng ${ }^{2,3}$
}

Epithelial-mesenchymal transition (EMT) occurs during adult tissue remodeling responses including carcinogenesis and fibrosis. Existing evidence reveals that hepatocytes can undergo EMT in adult liver, which is critically involved in chronic liver injury. We herein established a hypoxia-induced EMT model in human LO2 hepatocytes treated with cobalt chloride $\left(\mathrm{CoCl}_{2}\right)$ in vitro, and evaluated the effects of curcumin, a natural antifibrotic compound, on hepatocyte EMT and explored the underlying molecular mechanisms. We found that $\mathrm{CoCl}_{2}$ at non-toxic doses induced a mesenchymal cell phenotype in hepatocytes and upregulated several mesenchymal markers including $a$-smooth muscle actin, vimentin, N-cadherin, fibronectin and Snail (an EMT-related transcription factor), but downregulated the epithelial marker E-cadherin in hepatocytes. However, curcumin reversed the morphological changes, abrogated the increased expression of mesenchymal markers, and rescued E-cadherin expression in $\mathrm{CoCl}_{2}$-treated hepatocytes, suggesting the inhibition of hepatocyte EMT in vitro. We further found that curcumin interfered with the transforming growth factor- $\beta$ (TGF- $\beta$ ) signaling by reducing the expression of TGF- $\beta$ receptor I and inhibiting the expression and phosphorylation of Smad 2 and Smad3. Use of SB431542, a specific inhibitor of TGF- $\beta$ receptor I, demonstrated that interference with the TGF- $\beta / \mathrm{Smad}$ pathway was associated with curcumin suppression of hepatocyte EMT. Our in vivo data showed that curcumin affected hepatic EMT in rat fibrotic liver caused by carbon tetrachloride, which was associated with the inhibition of TGF- $\beta / \mathrm{Smad}$ signaling. These findings characterized a novel mechanism by which curcumin modulated hepatocyte EMT implicated in treatment of liver fibrosis.

Laboratory Investigation (2015) 95, 1234-1245; doi:10.1038/labinvest.2015.107; published online 24 August 2015

Epithelial-mesenchymal transition (EMT) describes a biological process that allows polarized epithelial cells to undergo multiple biochemical changes that enable them gradually to lose typical epithelial characteristics and acquire mesenchymal cell phenotype. ${ }^{1}$ EMT refers mainly to changes in cell shape and adhesive properties and thus is merely a manifestation of the inherent plasticity of cells. Completion of EMT requires a carefully orchestrated series of events that eventually lead to widespread changes in gene expression. During EMT, epithelial cells express mesenchymal markers such as $\alpha$-smooth muscle actin ( $\alpha$-SMA) and vimentin, and demonstrate altered distribution of molecules that mediate cell-cell and cell-matrix contacts, such as downregulation of E-cadherin and upregulation of $\mathrm{N}$-cadherin. ${ }^{2}$

Abundant studies have demonstrated that EMT represents an important origin of the mesenchymal cells that participate in tissue repair and pathological processes, notably tissue fibrosis, tumor invasiveness, and metastasis. ${ }^{3}$ There is solid experimental evidence that hepatocytes can be induced to undergo EMT in adult liver. It has been found that hepatocytes in injured adult liver acquired a migratory phenotype and moved into the hepatic mesenchyme where they exhibited characteristics of mesenchymal cells. ${ }^{4}$ Studies also demonstrated that hepatocytes could contribute to the

${ }^{1}$ Department of Science, Technology and Education, The Third Affiliated Hospital of Nanjing University of Chinese Medicine, Nanjing, China; ${ }^{2}$ Department of Pharmacology, School of Pharmacy, Nanjing University of Chinese Medicine, Nanjing, China; ${ }^{3}$ Jiangsu Key Laboratory for Pharmacology and Safety Evaluation of Chinese Materia Medica, Nanjing University of Chinese Medicine, Nanjing, China; ${ }^{4}$ Department of Pharmacy, School of Pharmacy, Nanjing University of Chinese Medicine, Nanjing, China and

${ }^{5}$ School of Hanlin, Nanjing University of Chinese Medicine, Taizhou, China

Correspondence: Dr S Zheng, PhD, MD, Department of Pharmacology, School of Pharmacy, Nanjing University of Chinese Medicine, 138 Xianlin Avenue, Nanjing, Jiangsu 210023, China.

E-mail: nytws@163.com

${ }^{6}$ These authors contributed equally to this work.

Received 5 November 2014; revised 5 May 2015; accepted 15 June 2015 
accumulation of activated fibroblasts via EMT, which had a functional role in the progression of fibrosis in two different mouse models for chronic liver disease. ${ }^{5,6}$ These data suggest that EMT modulates the outcome of chronic liver injury and may be a promising therapeutic target for reduction of liver fibrosis. In contrast, there is also observation that the collagen-expressing cells were not derived from hepatocytes through EMT during liver fibrosis in transgenic mice, questioning the contribution of hepatocyte EMT to extracellular matrix (ECM) deposition and tissue repair in liver fibrosis. $^{7}$

It is known that hypoxia as a critical microenvironmental factor promotes EMT and metastatic phenotypes in human cancer cells. ${ }^{1}$ Transforming growth factor- $\beta$ (TGF- $\beta$ ) signaling has also been demonstrated to provoke EMT in many types of epithelial cells, ${ }^{8}$ which is initiated by the binding of active TGF- $\beta$ to its type II receptor (TGF- $\beta$ RII), leading to activation of its type I receptor (TGF- $\beta$ RI). The latter, in turn, phosphorylates Smad2 and Smad3, which subsequently form a complex with Smad4 and migrate into the nucleus to regulate target genes. ${ }^{9}$ We previously reported that curcumin, the yellow pigment in turmeric, protected the liver against fibrogenic insults and could be a promising dietary supplement for hepatocyte protection. ${ }^{10}$ Given that intervention of hepatocyte EMT may be implicated in the attenuation of liver fibrotic injury, our present study was aimed to examine the effects of curcumin on cobalt chloride $\left(\mathrm{CoCl}_{2}\right)$-mediated hypoxia-induced EMT in human hepatocytes in culture and to explore the underlying molecular events. Then, we validated the association between curcumin modulation of hepatic EMT and reduction of liver fibrosis caused by carbon tetrachloride $\left(\mathrm{CCl}_{4}\right)$ in rats. Our results provided novel insights into curcumin intervention of liver fibrosis.

\section{MATERIALS AND METHODS Reagents and Antibodies}

Curcumin was obtained from Sigma-Aldrich (St Louis, MO, USA). TGF- $\beta$ RI inhibitor SB431542 was obtained from Selleck Chemicals (Houston, TX, USA). The two compounds were dissolved with dimethylsulfoxide (Sinopharm Chemical Reagent, Shanghai, China) for experiments. $\mathrm{CoCl}_{2}$ was obtained from Beijing Dingguo Changsheng Biotechnology (Beijing, China), and dissolved with deionized water for experiments. Antibodies and their sources are as follows: vimentin, N-cadherin, TGF- $\beta$ RI, TGF- $\beta$ RII, p-Smad2, Smad2, p-Smad3, and Smad3 (Bioworld Technology, Nanjing, China); $\alpha$-SMA, fibronectin, and Snail (Epitomics, San Francisco, CA, USA); E-cadherin (GeneTex, San Antonio, TX, USA); collagen I (Calbiochem, Darmstadt, Germany), and $\beta$-actin (Sigma-Aldrich).

\section{Cell Culture}

Human LO2 hepatocytes were purchased from the Cell Bank of Chinese Academy of Sciences (Shanghai, China) and were cultured in Dulbecco's modified Eagle medium (Invitrogen, Grand Island, NY, USA) supplemented with 10\% fetal bovine serum (Wisent Biotechnology, Nanjing, China), $100 \mathrm{U} / \mathrm{ml}$ penicillin and $100 \mathrm{mg} / \mathrm{ml}$ streptomycin, and grown in a $95 \%$ air and $5 \% \mathrm{CO}_{2}$ humidified atmosphere at $37^{\circ} \mathrm{C}$. Cell morphology was assessed using an inverted microscope with a Leica Qwin System (Leica, Germany).

\section{Cell Proliferation Assay}

LO2 cells were seeded in 96-well plates and cultured in Dulbecco's modified Eagle medium with $10 \%$ fetal bovine serum for $24 \mathrm{~h}$, and then were treated with vehicle, $\mathrm{CoCl}_{2}$, and/or curcumin at indicated concentrations for 24 or $72 \mathrm{~h}$. Then, the medium was replaced with $100 \mu \mathrm{l}$ phosphatebuffered saline containing $0.5 \mathrm{mg} / \mathrm{ml} 3$-(4,5-dimethylthiazol2-yl)-2,5-diphenyl tetrazolium bromide (MTT) incubating at $37^{\circ} \mathrm{C}$ for $4 \mathrm{~h}$. Next, the crystals were dissolved with $200 \mu \mathrm{l}$ dimethylsulfoxide. The spectrophotometric absorbance at $490 \mathrm{~nm}$ was measured by a SPECTRAmax ${ }^{\mathrm{TM}}$ microplate spectrophotometer (Molecular Devices, Sunnyvale, CA, USA). Results were from three independent experiments and each experiment had six replicates.

\section{Measurement of Hepatic Enzyme Levels}

LO2 cells were seeded in 96-well plates and cultured in Dulbecco's modified Eagle medium supplemented with 10\% fetal bovine serum for $24 \mathrm{~h}$, and then treated with vehicle or $\mathrm{CoCl}_{2}$ at indicated concentrations for $24 \mathrm{~h}$. The levels (U/g prot) of alanine aminotransferase, aspartate aminotransferase, and alkaline phosphatase in culture medium were measured using enzyme-linked immunosorbent assay methods according to the kit protocols (Nanjing Jiancheng Bioengineering Institute, Nanjing, China). Results were from three independent experiments and each experiment had six replicates.

\section{Animal Procedures and Treatments}

Animal experimental procedures were approved by the institutional and local committee on the care and use of animals of Nanjing University of Chinese Medicine (Nanjing, China), and all animals received humane care according to the National Institutes of Health (USA) guidelines. Male Sprague-Dawley rats (200-250 g body weight) were obtained from Shanghai Slac Laboratory Animal (Shanghai, China). A mixture of $\mathrm{CCl}_{4}(0.1 \mathrm{ml} / 100 \mathrm{~g}$ body weight $)$ and olive oil (1:1 $(\mathrm{v} / \mathrm{v}))$ was used to induce liver fibrosis in rats. Thirty rats were randomly divided into five groups (six rats per group). Group 1 was the vehicle control in which rats were not administrated $\mathrm{CCl}_{4}$ or curcumin but intraperitoneally (i.p.) injected with olive oil. Group 2 was the $\mathrm{CCl}_{4}$ group in which rats were i.p. injected with $\mathrm{CCl}_{4}$ without curcumin treatment. Groups 3, 4, and 5 were treatment groups in which rats were i.p. injected with $\mathrm{CCl}_{4}$ and orally given curcumin at 100,200 , and $400 \mathrm{mg} / \mathrm{kg}$, respectively. Rats in groups $2-5$ were i.p. injected with $\mathrm{CCl}_{4}$ every other day for 8 weeks. Curcumin was suspended in phosphate-buffered saline and given once daily by gavage 
during the weeks $5-8$. The control animals in groups 1 and 2 were i.p. injected with the same volume of olive oil and oral administration of the same volume of phosphate-buffered saline. At the end of experiment, rats were killed after being anesthetized by i.p. injection with pentobarbital $(50 \mathrm{mg} / \mathrm{kg})$. Blood was collected and livers were isolated. A small portion of the liver was removed for histopathological and immunohistochemical studies by fixation with $10 \%$ formalin and subsequently embedded with paraffin. The remaining liver was cut in pieces and rapidly frozen with liquid nitrogen for extraction of hepatic proteins.

\section{Liver Histopathology}

Liver tissues were fixed in 10\% neutral buffered formalin and embedded in paraffin. Liver slices of $5 \mu \mathrm{m}$ thickness were prepared and stained with hematoxylin-eosin using standard methods. Images were taken in a blinded manner at random fields by a pathologist at Jiangsu Hospital of Traditional Chinese Medicine (Nanjing, China). Representative views of liver sections are shown.

\section{Immunofluorescence Staining}

For staining with cells, LO2 cells were seeded in six-well plates and cultured in Dulbecco's modified Eagle medium with 10\% fetal bovine serum for $24 \mathrm{~h}$, and then were treated with dimethylsulfoxide, $\mathrm{CoCl}_{2}$, and/or curcumin at indicated concentrations for $24 \mathrm{~h}$. Cells were incubated with primary antibodies overnight at $4{ }^{\circ} \mathrm{C}$. After three washes with phosphate-buffered saline, cells were incubated with $\mathrm{Cy3}-$ conjugated goat anti-rabbit IgG (1:32 dilution; Wuhan Boster Biological Technology, Wuhan, China) at room temperature for $2 \mathrm{~h}$. The control cells were incubated with the secondary antibody alone. Then, the Hoechst 33342 reagent (Beyotime Institute of Biotechnology, Haimen, China) was used to stain the nucleus. For staining with liver tissues, thin sections $(5 \mu \mathrm{m})$ after deparaffinization were blocked with $1 \%$ bovine serum albumin, and then were incubated with corresponding primary antibodies and fluorescence-conjugated secondary antibodies in succession similar to the above-described protocol. Cells or sections were visualized with a fluorescence microscope (Nikon, Tokyo, Japan), and images were taken in a blinded manner at random fields. Representative views with positive staining are shown.

\section{Western Blot Analyses}

Whole cell protein extracts were prepared from cultured cells or liver tissues. The protein levels were determined using a BCA assay kit (Pierce, USA). Proteins (50 $\mu$ g per well) were separated by SDS-polyacrylamide gel, transferred to a PVDF membrane (Millipore, Burlington, MA, USA), and blocked with $5 \%$ skim milk in Tris-buffered saline containing $0.1 \%$ Tween 20. Target proteins were detected by corresponding primary antibodies, and subsequently by horseradish peroxidase-conjugated secondary antibodies. Protein bands were visualized using chemiluminescence reagent (Millipore) by manual film exposure or Bio-Rad Universal Hood II DOC Electrophoresis Imaging Cabinet. Equivalent loading was confirmed using an antibody against $\beta$-actin. The levels of target protein bands were densitometrically determined using Image Lab Software 3.0. The variation in the density of bands was expressed as fold changes compared with the control in the blot after normalization to $\beta$-actin. Presented blots are representative of three independent experiments.

\section{Statistical Analysis}

Data were presented as mean \pm s.d. The significance of difference was determined by one-way ANOVA with the post hoc Dunnett's test for multiple comparisons. Values of $P<0.05$ were considered to be statistically significant.

\section{RESULTS \\ $\mathrm{CoCl}_{2}$ Induces EMT in Hepatocytes In Vitro}

$\mathrm{CoCl}_{2}$ is a commonly used hypoxia-mimetic agent. ${ }^{11-13} \mathrm{We}$ aimed to establish an EMT model induced by $\mathrm{CoCl}_{2-}$ mediated hypoxia in hepatocytes. We initially performed MTT assay to determine the dose range for $\mathrm{CoCl}_{2}$ not affecting hepatocyte proliferation. Results showed that LO2 cell viability was not significantly repressed by $\mathrm{CoCl}_{2}$ at doses lower than $200 \mu \mathrm{M}$ for 24 or $72 \mathrm{~h}$ treatment duration (Figure 1a). Measurement of hepatic enzymes alanine aminotransferase, aspartate aminotransferase, and alkaline phosphatase in the supernatant of $\mathrm{CoCl}_{2}$-treated $\mathrm{LO} 2$ cells demonstrated that their levels were not significantly elevated by $\mathrm{CoCl}_{2}$ within a wide dose range $(<500 \mu \mathrm{M})$ (Figure 1b). These results indicated that $\mathrm{CoCl}_{2}$ had low toxicity to $\mathrm{LO} 2$ hepatocytes in culture. We subsequently used $\mathrm{CoCl}_{2}$ at $100 \mu \mathrm{M}$ to cause hypoxia for inducing EMT in hepatocytes. We observed that $\mathrm{CoCl}_{2}$-treated $\mathrm{LO} 2$ cells underwent remarkable morphological changes from cobblestone-like to spindle-like shape with extension of stimulation time (Figure 1c), suggesting a mesenchymal cell phenotype in LO2 cells. Western blot assays were carried out to examine the expression of EMT-related molecules, showing that mesenchymal markers $\alpha$-SMA, vimentin, $\mathrm{N}$-cadherin, fibronectin, and Snail (a well-established transcription factor promoting $\mathrm{EMT}^{14}$ ) were upregulated but E-cadherin was downregulated by $\mathrm{CoCl}_{2}$ treatment in LO2 cells (Figure 1d). These data collectively suggested that $\mathrm{CoCl}_{2}$-mediated hypoxia induced EMT in LO2 cells in vitro.

\section{Curcumin Inhibits $\mathrm{CoCl}_{2}$-Induced EMT in Hepatocytes In Vitro}

We subsequently investigated the effects of curcumin on $\mathrm{CoCl}_{2}$-induced EMT in LO2 cells. MTT assays showed that curcumin at doses lower than $70 \mu \mathrm{M}$ did not apparently affect LO2 cell proliferation in the absence or presence of $\mathrm{CoCl}_{2}$ (Figure 2a and b). We thus set curcumin at doses lower than $30 \mu \mathrm{M}$, which was relatively far from the toxic dose, to investigate its effects on hepatocyte EMT and the underlying mechanisms. Morphological evaluations revealed that 

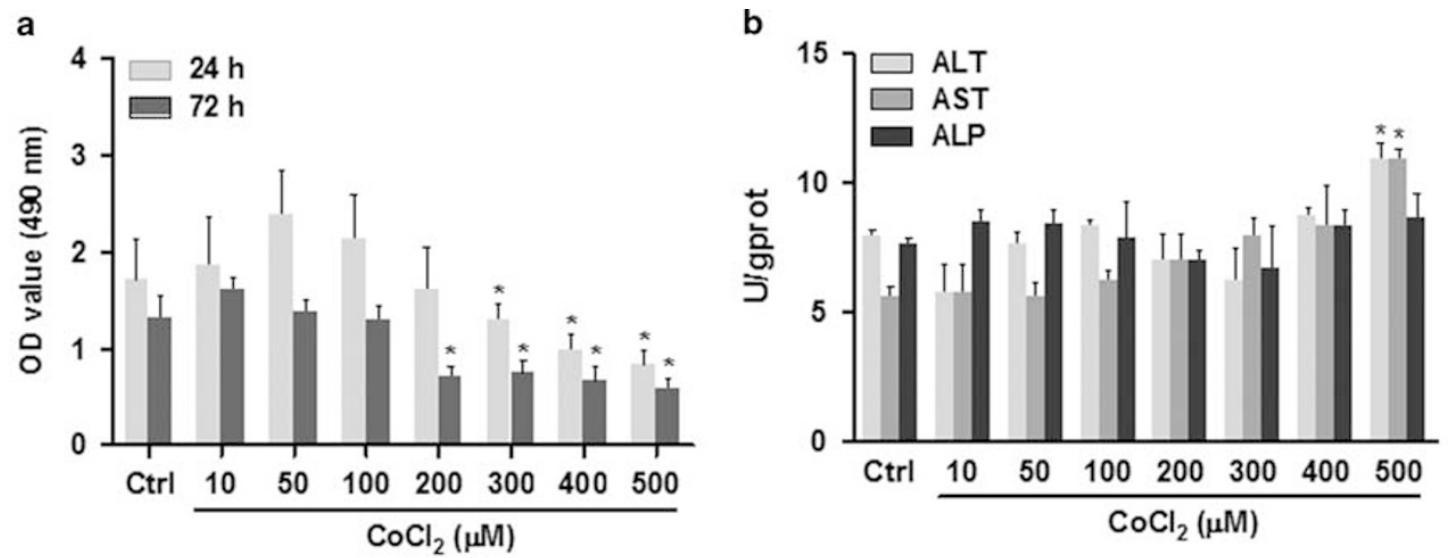

c $\mathrm{CoCl}_{2}(100 \mu \mathrm{M})$
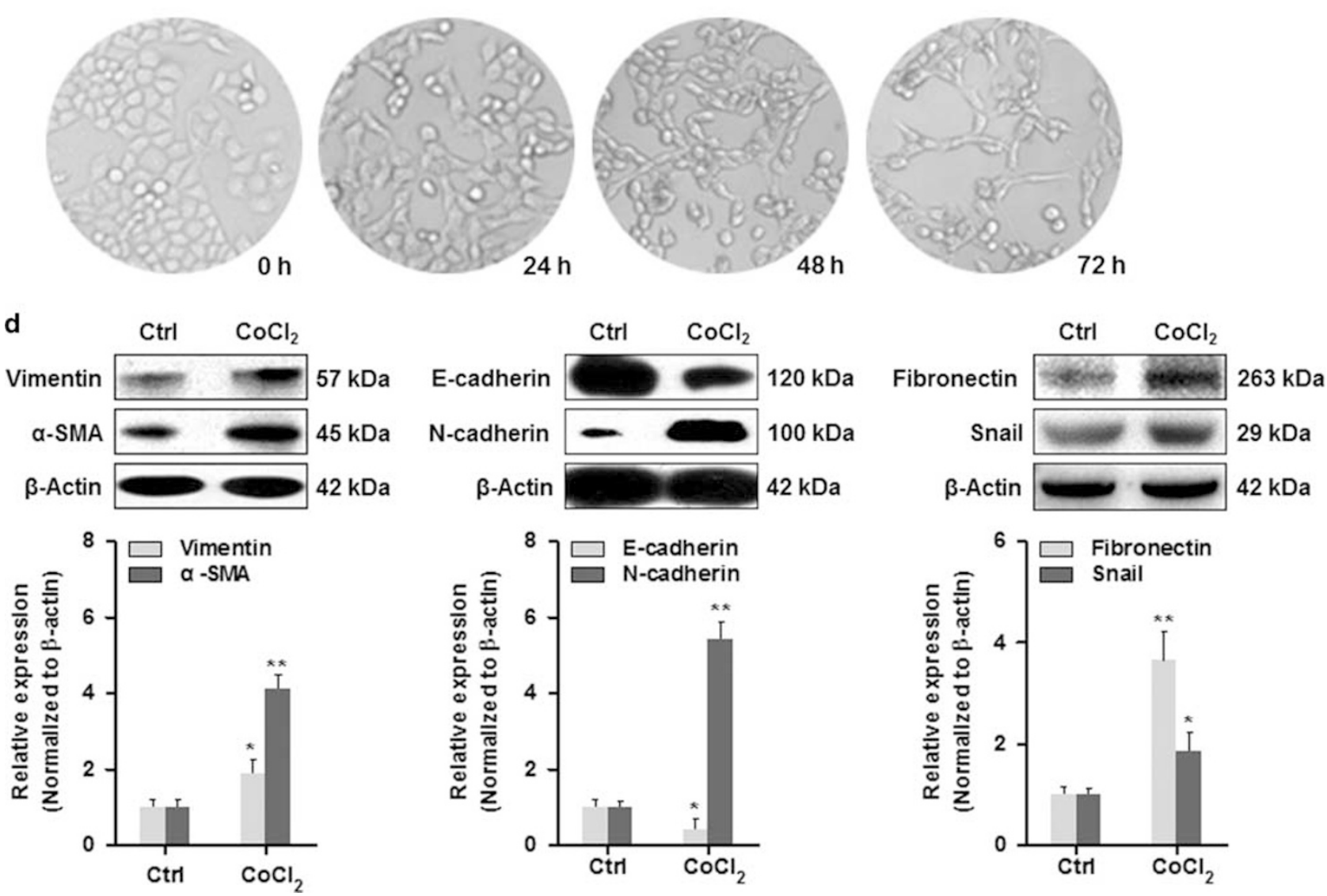

Figure $1 \mathrm{CoCl}_{2}$ induces EMT in hepatocytes in vitro. (a) MTT assay. LO2 cells were treated with vehicle or $\mathrm{CoCl}_{2}$ at indicated concentrations for 24 or $72 \mathrm{~h}$. ${ }^{*} P<0.05$ versus control. (b) Measurement of hepatic enzyme levels in cell supernatant. $\mathrm{LO} 2$ cells were treated with vehicle or $\mathrm{CoCl}_{2}$ at indicated concentrations for $24 \mathrm{~h}$. ${ }^{*} P<0.05$ versus control. (c) Cell morphology assessment. LO2 cells were treated with $\mathrm{CoCl}_{2}$ at $100 \mu \mathrm{M}$ for indicated time durations (original magnification $\times 100$ ). (d) LO2 cells were treated with vehicle or $\mathrm{CoCl}_{2}$ at $100 \mu \mathrm{M}$ for $24 \mathrm{~h}$. Western blot analyses of EMT-related proteins. $\beta$-Actin was used as an invariant control for equal loading. Blots are representative of three independent experiments with densitometry showing the mean \pm s.d. ${ }^{*} P<0.05$ versus control, ${ }^{* *} P<0.01$ versus control. ALP, alkaline phosphatase; ALT, alanine aminotransferase; $a-S M A$, $a$-smooth muscle actin; AST, aspartate aminotransferase; EMT, epithelial-mesenchymal transition; MTT, 3-(4,5-dimethylthiazol-2-yl)-2,5-diphenyl tetrazolium bromide.

curcumin at $30 \mu \mathrm{M}$ significantly reversed the spindle-like mesenchymal shape caused by $\mathrm{CoCl}_{2}$ in $\mathrm{LO} 2$ cells (Figure 2c). In addition to the morphological evidence, curcumin dosedependently diminished the expression of vimentin, $\alpha$-SMA,
$\mathrm{N}$-cadherin, and fibronectin, but restored E-cadherin expression in $\mathrm{CoCl}_{2}$-stimulated $\mathrm{LO} 2$ cells (Figure 2d). However, the expression of Snail was not significantly affected by curcumin in the cellular model (Figure 2d). Additional 
immunofluorescence experiments provided consistent data that curcumin at $30 \mu \mathrm{M}$ abolished $\mathrm{CoCl}_{2}$-caused increase in the expression of vimentin, $\alpha$-SMA, and $\mathrm{N}$-cadherin, and rescued E-cadherin expression in LO2 cells (Figure 3). Taken together, these results indicated that curcumin inhibited $\mathrm{CoCl}_{2}$-induced EMT in $\mathrm{LO} 2$ cells in vitro.

\section{Interference with TGF- $\beta /$ Smad Signaling Is Associated with Curcumin Inhibition of $\mathrm{CoCl}_{2}$-Induced EMT in $\mathrm{LO2}$ Cells In Vitro}

We next explored the molecular events underlying curcumin inhibition of $\mathrm{CoCl}_{2}$-induced EMT in LO2 cells. TGF- $\beta / \mathrm{Smad}$ signaling has been demonstrated to have a key role during EMT. ${ }^{15}$ We herein found that TGF- $\beta$ RI, TGF- $\beta$ RII, and the downstream Smad and their phosphorylation were all upregulated in $\mathrm{CoCl}_{2}$-treated LO2 cells (Figure 4a). Curcumin reduced the expression of TGF- $\beta$ RI, Smad2, Smad3, and their phosphorylation dose-dependently, indicating curcumin interference with the TGF- $\beta$ signaling in $\mathrm{CoCl}_{2}$-stimulated LO2 cells, but the TGF- $\beta$ RII levels were unaffected by curcumin treatment (Figure $4 \mathrm{a}$ ). We further used a TGF- $\beta$ RI-specific inhibitor, SB431542, to test the link between the signaling blockade and inhibition of hepatocyte EMT. Results demonstrated that pharmacological inhibition of TGF- $\beta$ RI reduced the expression of vimentin, $\alpha$-SMA, $\mathrm{N}$-cadherin, and fibronectin, and enhanced the expression of E-cadherin in $\mathrm{CoCl}_{2}$-treated LO2 cells (Figure 4b). SB431542 mimicked the curcumin effects on these marker proteins and strengthened the curcumin effects to different extends (Figure $4 \mathrm{~b}$ ). Altogether, these observations suggested that curcumin inhibition of $\mathrm{CoCl}_{2}$-induced EMT in LO2 hepatocytes was associated with interference with TGF- $\beta /$ Smad signaling in vitro.
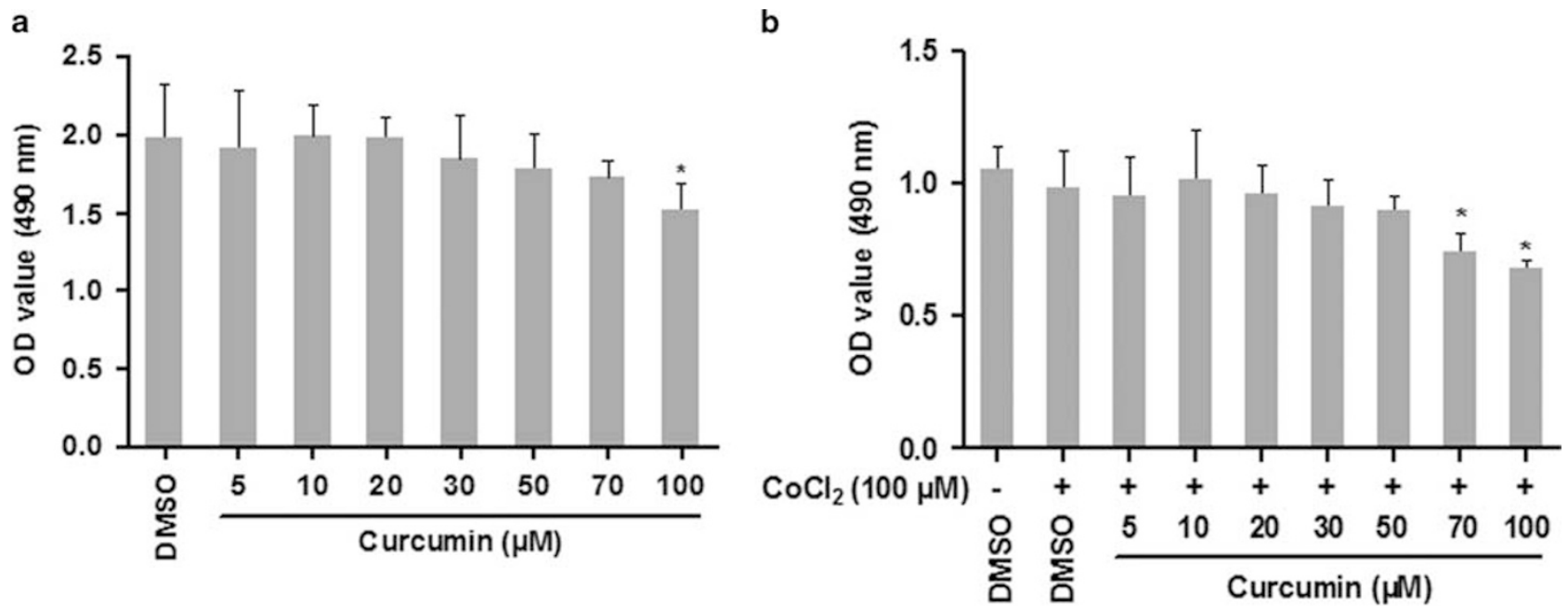

c
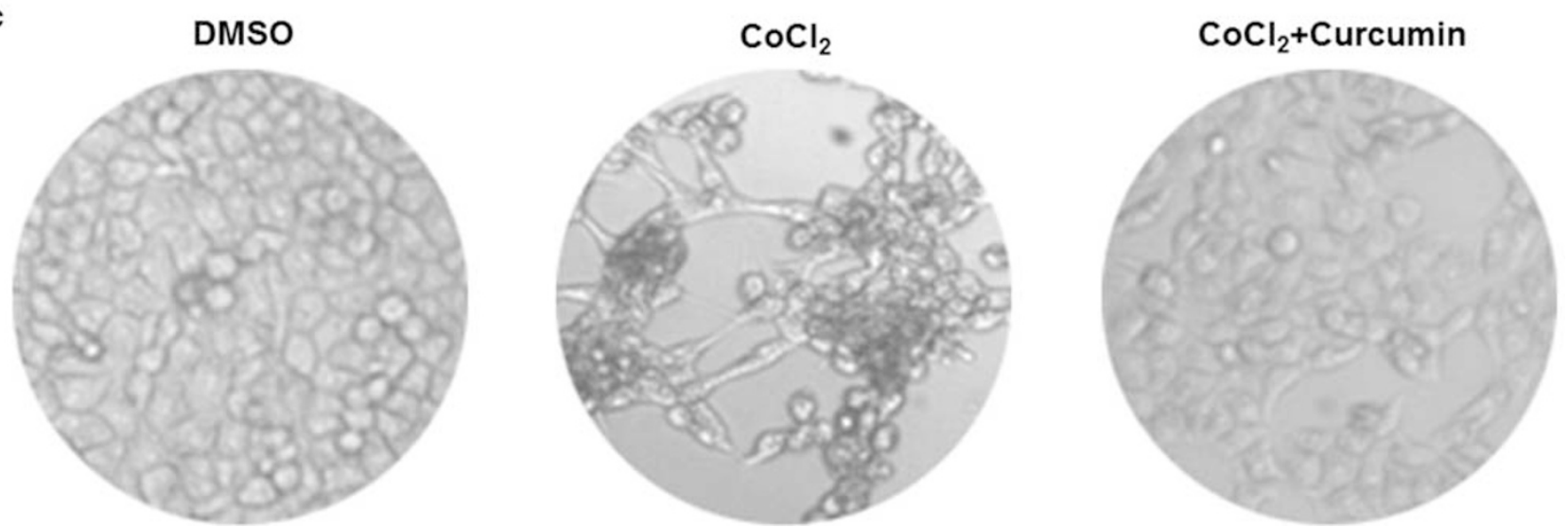

Figure 2 Curcumin inhibits $\mathrm{CoCl}_{2}$-induced EMT in hepatocytes in vitro. (a) MTT assay. LO2 cells were treated with DMSO or curcumin at indicated concentrations for $24 \mathrm{~h}$. ${ }^{*} P<0.05$ versus DMSO. (b) MTT assay. LO2 cells were treated with DMSO, $\mathrm{CoCl}_{2}(100 \mu \mathrm{M})$, and/or curcumin at indicated concentrations for $24 \mathrm{~h}$. ${ }^{*} P<0.05$ versus DMSO. (c) Cell morphology assessment. LO2 cells were treated with DMSO, $\mathrm{CoCl}_{2}(100 \mu \mathrm{M})$, and/or curcumin $(30 \mu \mathrm{M})$ for $72 \mathrm{~h}$ (original magnification $\times 100)$. (d) LO2 cells were treated with DMSO, $\mathrm{CoCl}_{2}(100 \mu \mathrm{M})$, and/or curcumin at indicated concentrations for $24 \mathrm{~h}$. Western blot analyses of EMT-related proteins. $\beta$-Actin was used as an invariant control for equal loading. Blots are representative of three independent experiments with densitometry showing the mean \pm s.d. ${ }^{\#} P<0.05$ versus DMSO, $\# \#<0.01$ versus DMSO, ${ }^{*} P<0.05$ versus DMSO+CoCl 2 , ${ }^{*} P<0.01$ versus $\mathrm{DMSO}+\mathrm{CoCl}_{2}$. a-SMA, a-smooth muscle actin; DMSO, dimethyl sulfoxide; EMT, epithelial-mesenchymal transition; MTT, 3-(4,5dimethylthiazol-2-yl)-2,5-diphenyl tetrazolium bromide. 
d

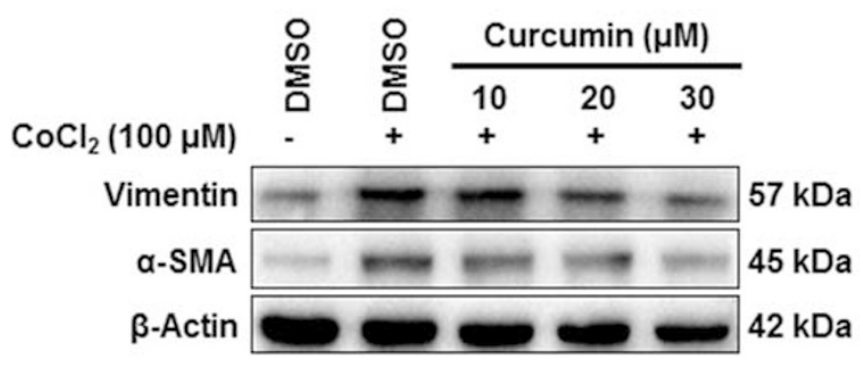

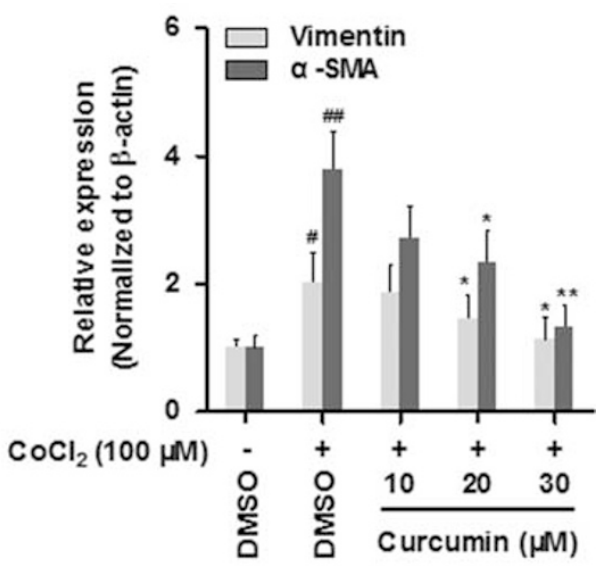
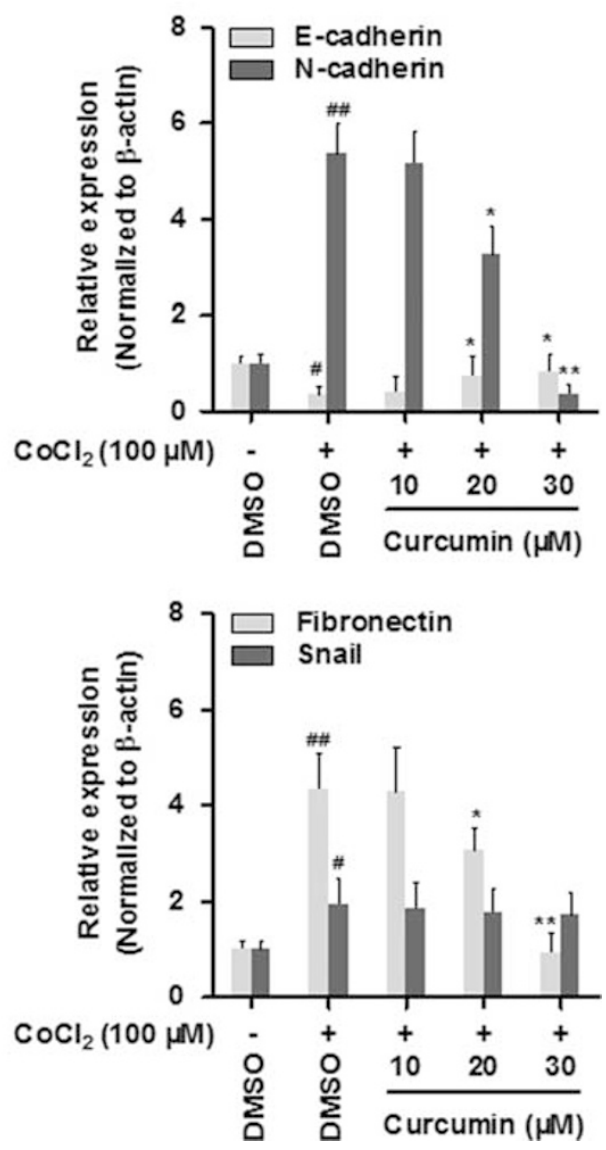

Figure 2 Continued.

\section{Curcumin Inhibits Hepatic EMT Associated with Interference with TGF- $\beta /$ Smad Signaling in Rat Fibrotic Liver Caused by $\mathrm{CCl}_{4}$}

Finally, we evaluated the effects of curcumin on hepatic EMT in liver injury and fibrogenesis in rats chronically injected with $\mathrm{CCl}_{4}$. Histological examination using hematoxylin-eosin staining showed that curcumin ameliorated the state of hepatic necrosis and fibrotic septa and improved liver histology (Figure 5a). Immunofluorescence staining for vimentin and $\alpha$-SMA demonstrated that the expression of
$263 \mathrm{kDa}$

$29 \mathrm{kDa}$

$42 \mathrm{kDa}$ these two EMT markers was increased in the injured liver, but was reduced by curcumin treatments (Figure $5 b$ ). Western blot analyses further showed that curcumin reduced the levels of mesenchymal markers vimentin, $\alpha$-SMA, N-cadherin, and fibronectin, and restored the levels of epithelial marker E-cadherin in rat fibrotic liver (Figure $5 \mathrm{c}$ ). The expression of collagen I, a primary indicator of ECM deposition in liver fibrosis, was also decreased by curcumin, indicating the attenuation of liver fibrotic injury (Figure $5 c$ ). Furthermore, curcumin decreased the protein abundance of TGF- $\beta$ RI, 

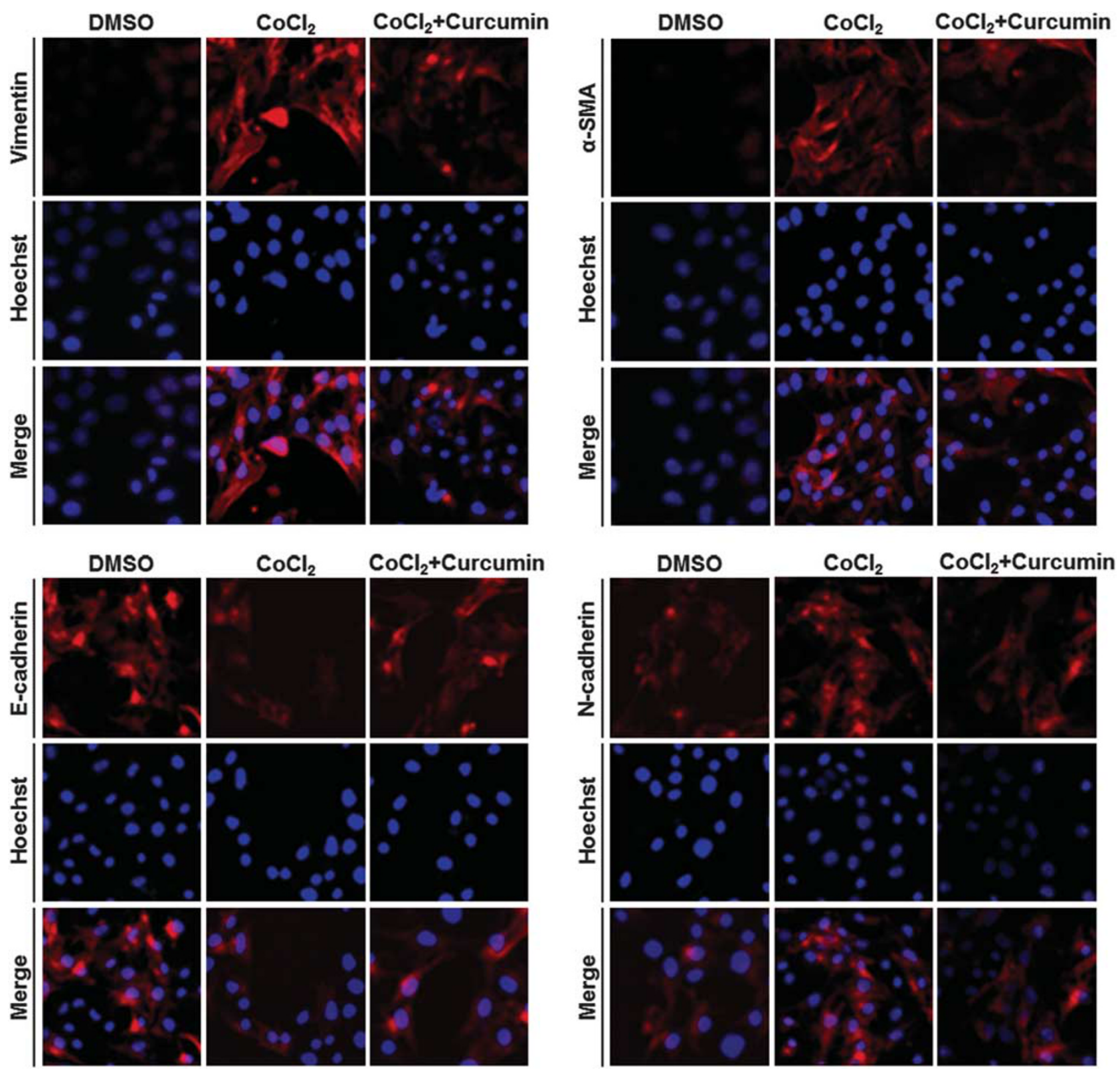

Figure 3 Immunofluorescence staining with antibodies against vimentin, $a$-SMA, E-cadherin, and N-cadherin. LO2 cells were treated with DMSO, CoCl 2 $(100 \mu \mathrm{M})$, and/or curcumin $(30 \mu \mathrm{M})$ for $24 \mathrm{~h}$. The Hoechst 33342 reagent was used to stain the nucleus. Images were taken in a blinded manner at random fields. Representative views with positive staining are shown (original magnification $\times 200$ ). a-SMA, a-smooth muscle actin; DMSO, dimethyl sulfoxide.

Smad2, and Smad3 in rat fibrotic liver (Figure 5c), which were consistent with the results obtained in $\mathrm{CoCl}_{2}$-treated LO2 hepatocytes. Taken together, these in vivo data confirmed that curcumin inhibited hepatic EMT associated with interference with TGF- $\beta /$ Smad signaling in $\mathrm{CCl}_{4}$-caused liver injury, contributing to reduction of liver fibrosis.

\section{DISCUSSION}

Hepatocyte EMT has been shown to be an important biological process in liver pathophysiology. ${ }^{16}$ Our current studies provide evidence supporting hepatocyte EMT in cultured human LO2 hepatocytes and in $\mathrm{CCl}_{4}$-induced experimental liver fibrosis in rats. Several growth factors have been demonstrated to be capable of inducing hepatocyte EMT, for example, treatment with sublethal doses of TGF- $\beta$ stimulated primary rat hepatocytes or hepatocyte cell lines to downregulate the expression of epithelial genes, upregulate the expression of mesenchymal genes, and acquire a migratory phenotype. ${ }^{15}$ In addition, substantial experimental evidence also supports hypoxia as an important stimulus of EMT in various pathological contexts. ${ }^{17,18}$ In the current study, we established hypoxia-induced EMT in hepatocytes 
a
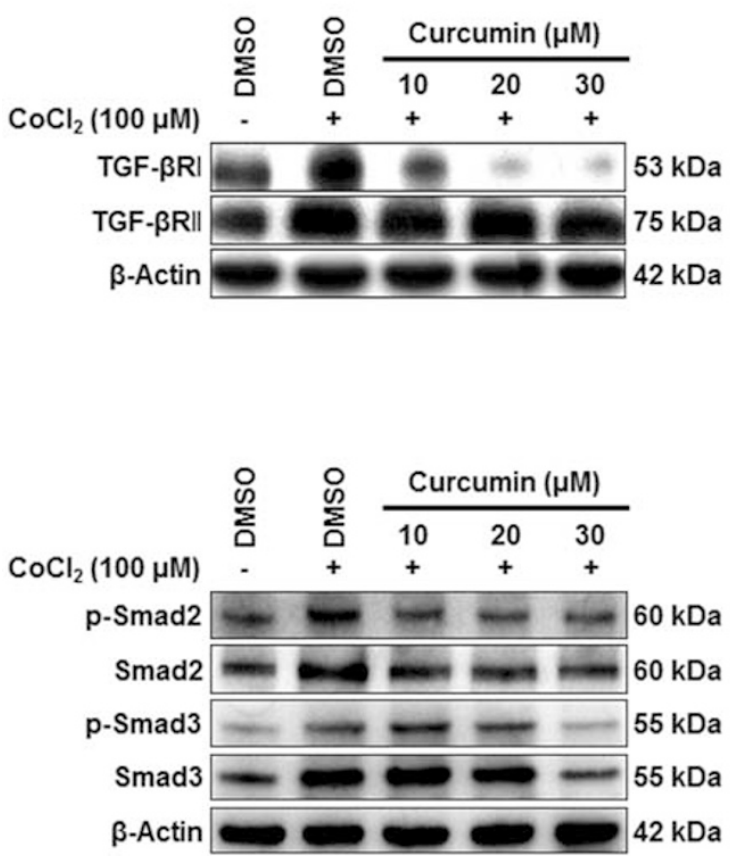

b
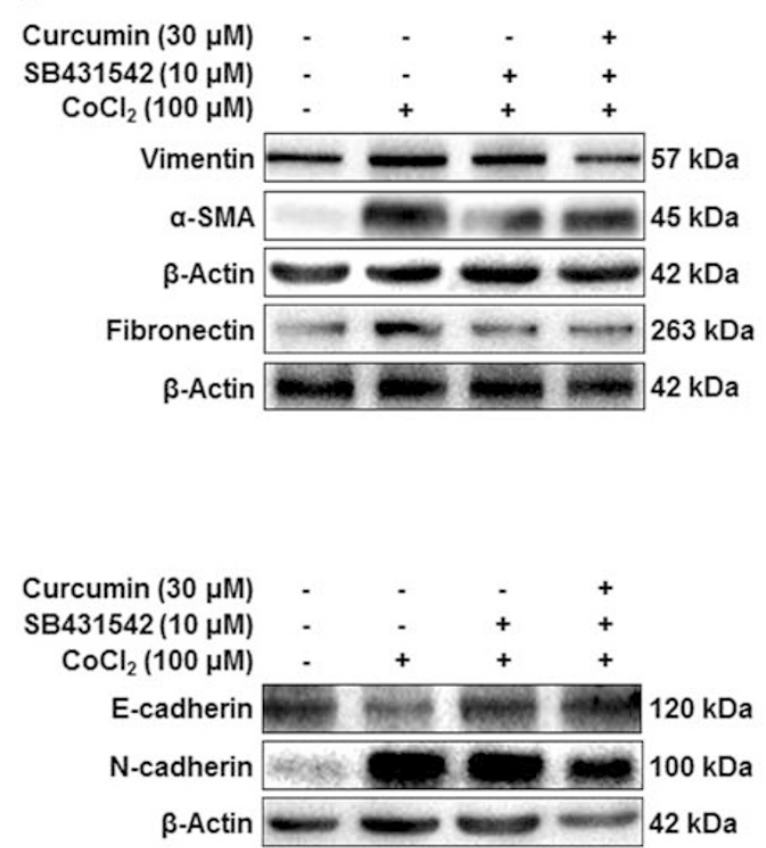
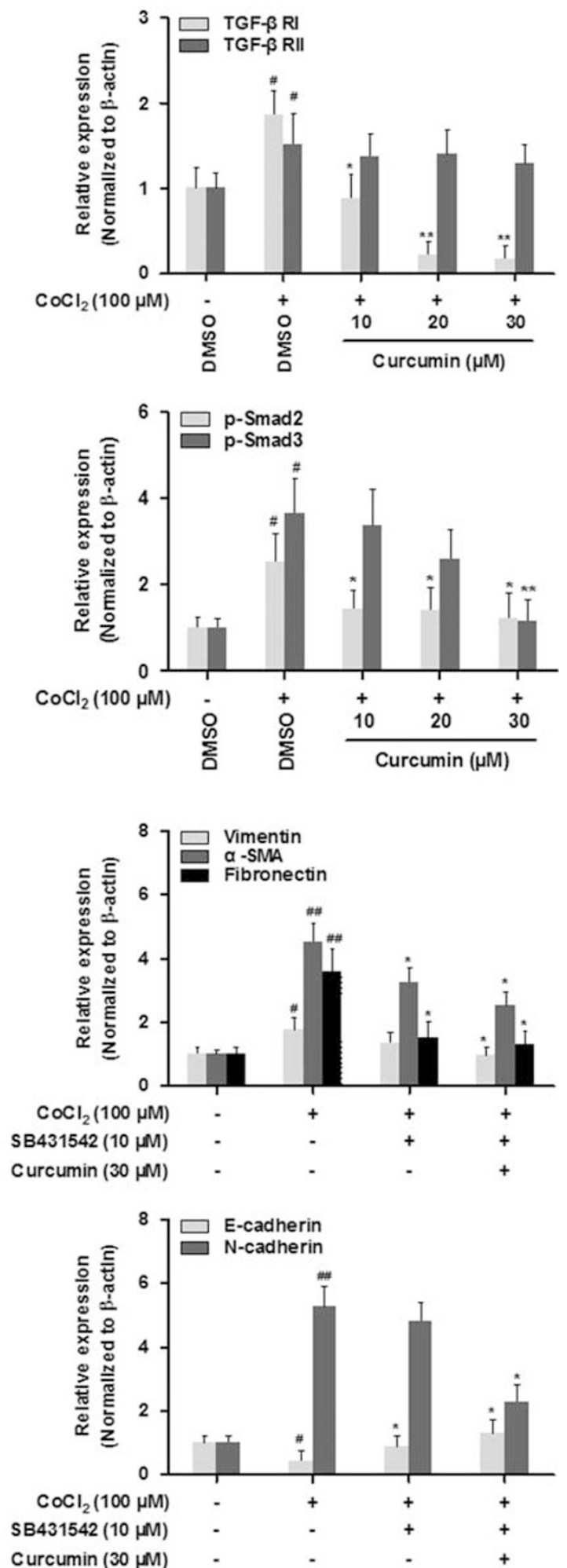

Figure 4 Interference with TGF- $\beta /$ Smad signaling is associated with curcumin inhibition of $\mathrm{CoCl}_{2}$-induced EMT in LO2 cells in vitro. (a) LO2 cells were treated with DMSO, $\mathrm{CoCl}_{2}(100 \mu \mathrm{M})$, and/or curcumin at indicated concentrations for $24 \mathrm{~h}$. Western blot analyses of TGF- $\beta / \mathrm{Smad}$ signaling molecules. $\beta$-Actin was used as an invariant control for equal loading. Representative blots were from three independent experiments with densitometry showing the mean \pm s.d. ${ }^{*} P<0.05$ versus DMSO, ${ }^{*} P<0.05$ versus $\mathrm{DMSO}+\mathrm{CoCl}_{2},{ }^{*} P<0.01$ versus $\mathrm{DMSO}+\mathrm{CoCl}_{2}$. (b) $\mathrm{LO} 2$ cells were treated with $\mathrm{DMSO}, \mathrm{CoCl}{ }_{2}$ $(100 \mu \mathrm{M})$, SB431542 $(10 \mu \mathrm{M})$, and/or curcumin $(30 \mu \mathrm{M})$ for $24 \mathrm{~h}$. Western blot analyses of EMT-related proteins. $\beta$-Actin was used as an invariant control for equal loading. Blots are representative of three independent experiments with densitometry showing the mean \pm s.d. ${ }^{\#} P<0.05$ versus DMSO,

${ }^{\# \#} P<0.01$ versus DMSO, ${ }^{*} P<0.05$ versus DMSO+CoCl 2. a-SMA, a-smooth muscle actin; DMSO, dimethyl sulfoxide; EMT, epithelial-mesenchymal transition. 
treated with $\mathrm{CoCl}_{2}$ in culture, because this chemical has been widely reported to be a hypoxia-mimicking agent blocking aerobic respiration and mitochondrial biogenesis within cells. ${ }^{11-13}$ Herein, the occurrence of EMT could be confirmed by the significant morphological changes and increased expression of mesenchymal makers $\alpha$-SMA, vimentin, $\mathrm{N}$-cadherin, fibronectin, and Snail in hepatocytes exposed to $\mathrm{CoCl}_{2}$ at doses without cytotoxicity in culture. Our results are also in line with a recent study demonstrating that exposure of primary mouse hepatocytes to $1 \%$ oxygen stimulated them to undergo EMT by activating hypoxia inducible factor- $1 \alpha{ }^{6}$

Mesenchymal hepatocytes could represent a candidate myofibroblast precursor pool producing ECM components in response to injury and chronic inflammation, and facilitate liver fibrosis. ${ }^{5}$ EMT of hepatocytes has been reported in rodents and patients with chronic liver diseases. ${ }^{19,20} \mathrm{We}$ previously reported that curcumin, a naturally occurring polyphenolic pigment, could inhibit hepatic stellate cell activation, protect hepatocytes, and prevent the liver from fibrogenic insults. ${ }^{10,21}$ However, effects of curcumin on hepatocyte EMT during liver fibrosis have not yet been investigated before. In the present study, we examined curcumin modulation of hepatocyte EMT and its association with the attenuation of chronic liver injury. We found that curcumin could apparently reverse the mesenchymal morphology of hepatocytes treated with $\mathrm{CoCl}_{2}$ and significantly reduce the expression of mesenchymal makers but restore the expression of epithelial marker E-cadherin, indicating that hypoxia-induced EMT of hepatocytes could be blocked by curcumin. However, the EMT-regulatory transcription factor Snail may have a role in $\mathrm{CoCl}_{2}$-induced hepatocyte EMT, but could not be a direct target molecule for curcumin. Consistently, two recent studies demonstrated that curcumin could also inhibit and reverse EMT in pancreatic cancer cells ${ }^{22}$ and breast cancer cells. ${ }^{23}$ These discoveries

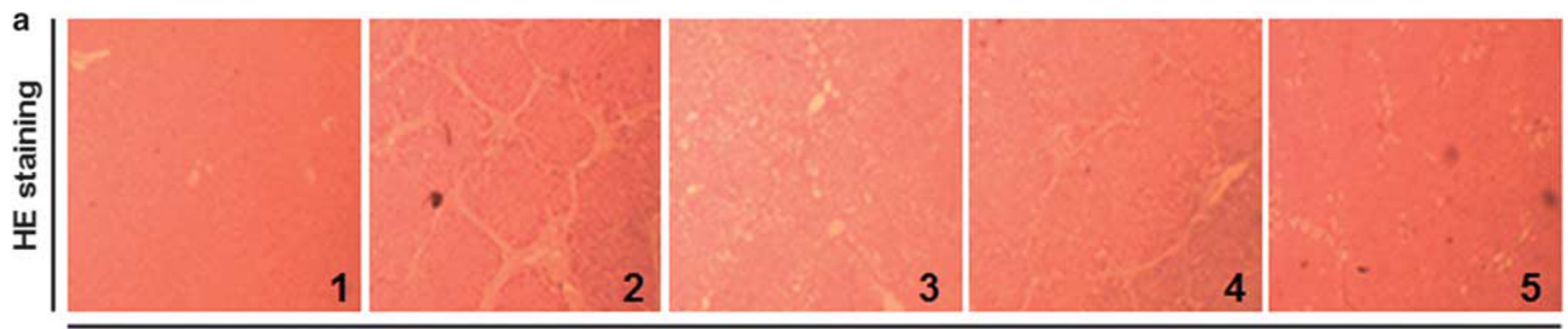

Animal groups
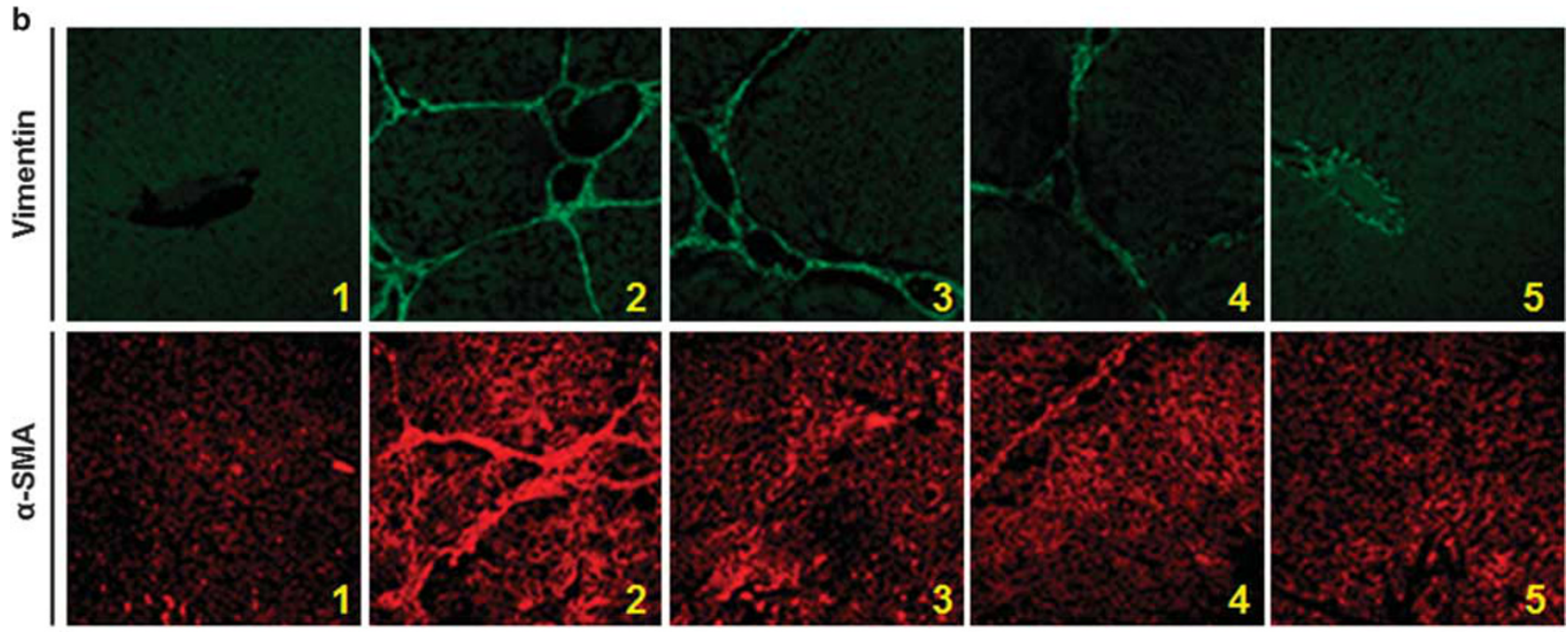

\section{Animal groups}

Figure 5 Curcumin inhibits hepatic EMT associated with interference with TGF- $\beta / \mathrm{Smad}$ signaling in rat fibrotic liver caused by $\mathrm{CCl}_{4}$. Rats were grouped: group 1, vehicle control (no $\mathrm{CCl}_{4}$, no treatment); group 2, model group (with $\mathrm{CCl}_{4}$, no treatment); group 3, curcumin-treated group (100 mg/kg+CCl $)$; group 4, curcumin-treated group (200 mg/kg+CCl $)$; group 5, curcumin-treated group $\left(400 \mathrm{mg} / \mathrm{kg}+\mathrm{CCl}_{4}\right)$. (a) Liver sections were stained with $\mathrm{HE}$ for histological assessment. Images were taken in a blinded manner at random fields. Representative views are shown (original magnification $\times 100)$. (b) Liver sections were stained with immunofluorescence using antibodies against vimentin and $\alpha$-SMA. Images were taken in a blinded manner at random fields. Representative views are shown (original magnification $\times 100$ ). (c) Western blot analyses of EMT-related proteins and TGF- $\beta /$ Smad signaling molecules. $\beta$-Actin was used as an invariant control for equal loading. Blots are representative of three independent experiments with densitometry showing the mean \pm s.d. ${ }^{\#} P<0.05$ versus group $1,{ }^{\# \#} P<0.01$ versus group $1,{ }^{*} P<0.05$ versus group $2,{ }^{* *} P<0.01$ versus group 2 . a-SMA, a-smooth muscle actin; EMT, epithelial-mesenchymal transition; HE, hematoxylin and eosin. 
C
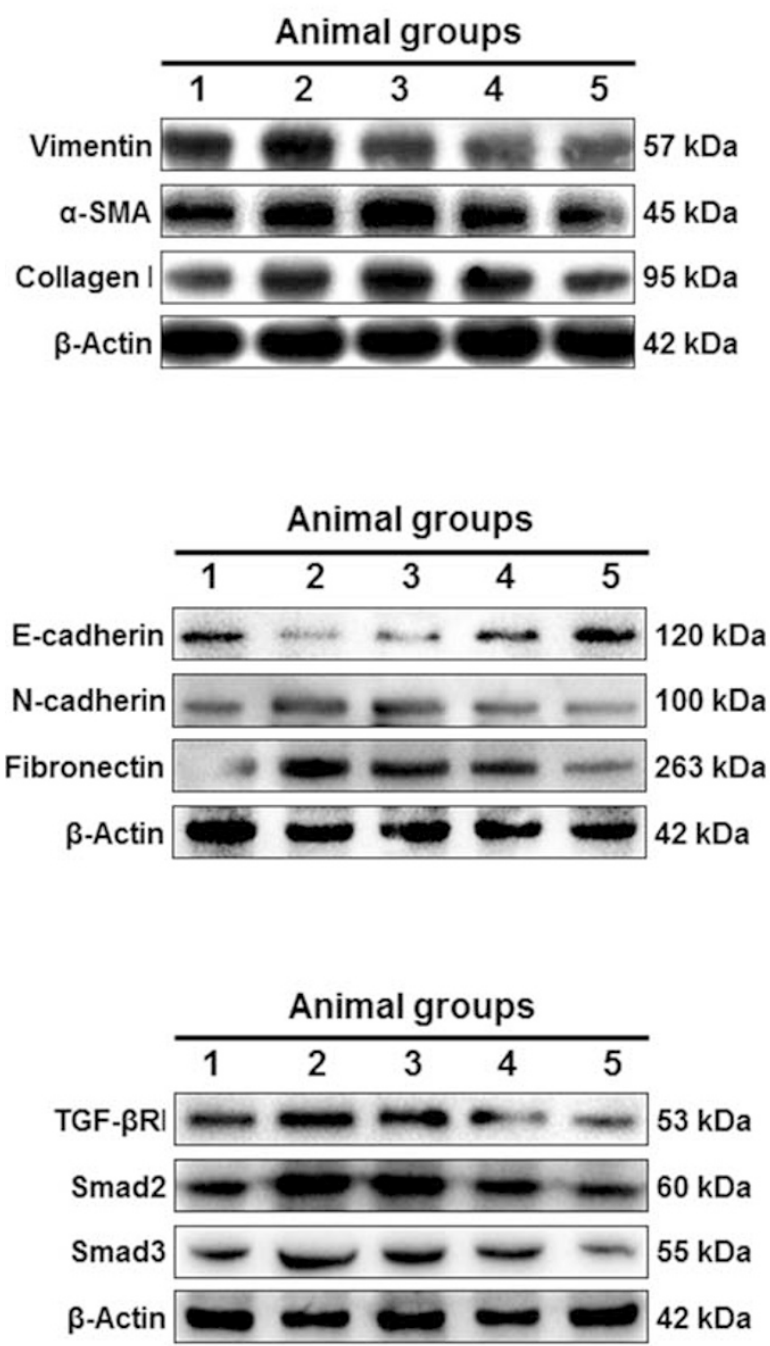

Figure 5 Continued.

suggested that the inhibition of EMT could be an important facet accounting for the multiple pharmacological effects of curcumin.

We further explored how curcumin inhibited hepatocyte EMT focusing on TGF- $\beta$ signaling. Our data showed that curcumin significantly reduced TGF- $\beta$ R1 expression in $\mathrm{CoCl}_{2}$-treated hepatocytes, which might disrupt the downstream signal transduction transmitted by Smad. Whether this interference was associated with the reversal of hepatocyte EMT was tested by pharmacological blockade of TGF- $\beta$ R1 by SB431542. This inhibitor rescued the expression of epithelial marker E-cadherin and abolished the expression of mesenchymal molecules $\mathrm{N}$-cadherin, vimentin, $\alpha$-SMA and fibronectin in $\mathrm{CoCl}_{2}$-treated hepatocytes. These data strongly suggested that suppression of TGF- $\beta$ R1 was involved in curcumin inhibition of hepatocyte EMT. Moreover, we found that phosphorylation of Smad2 and Smad3, two key
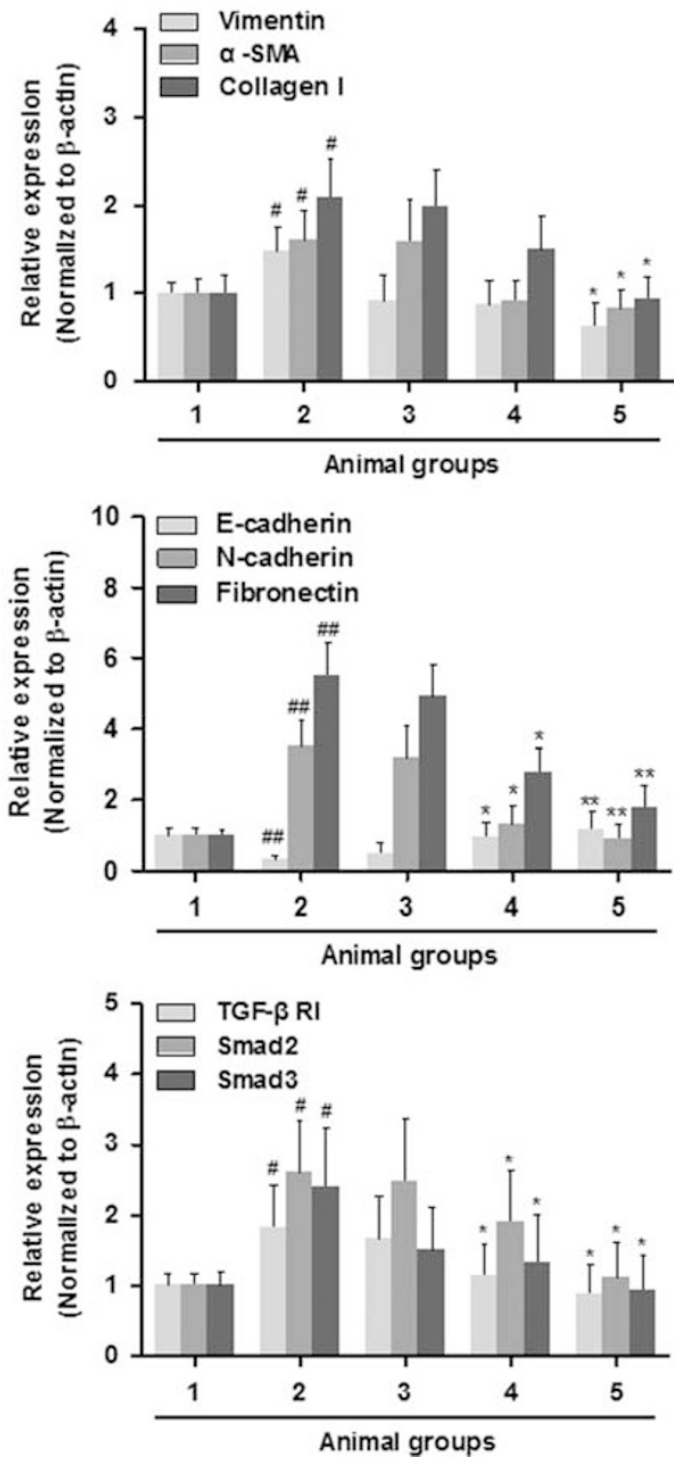

transmitters of TGF- $\beta$ receptors, was inhibited by curcumin, indicating the interruption of TGF- $\beta$ signal transduction. Interestingly, the expression of Smad2 and Smad3 was also reduced by curcumin. This could be probably explained by the recognition that the Smad proteins themselves are also the target genes of TGF- $\beta$ signaling. ${ }^{24}$ Therefore, inhibition of TGF- $\beta$ R 1 by curcumin within the treatment duration could also decrease the expression of Smad2 and Smad3. Collectively, the current data revealed that curcumin inhibited hypoxiainduced hepatocyte EMT linking to interference with TGF- $\beta$ signaling, which was in accordance with the finding that hypoxia stimulated hepatocyte EMT by a TGF- $\beta$ dependent mechanism during the development of liver fibrosis. ${ }^{6}$ On the other hand, TGF- $\beta$ signaling is one of the most powerful profibrogenic pathway for hepatic stellate cell activation and chronic liver diseases. ${ }^{25}$ Our prior studies demonstrated that curcumin disrupted TGF- $\beta$ signaling in 
hepatic stellate cells leading to reduced liver fibrosis. ${ }^{21}$ Taken the prior data with current findings together, it could be postulated that curcumin influenced the same pathway (TGF- $\beta$ signaling) but affected distinct biological processes in different liver cell types for the treatment of liver fibrosis.

We also investigated whether curcumin has any effects on hepatic EMT during chronic liver injury in rats with $\mathrm{CCl}_{4}{ }^{-}$ induced fibrosis. This could be helpful for verifying the role of inhibition of hepatocyte EMT in intervention of hepatic fibrosis. Our data showed that all the tested mesenchymal markers were significantly upregulated in rat fibrotic liver, suggesting that hepatic EMT occurred. However, the expression of these EMT markers was reduced by curcumin treatment. Moreover, curcumin improved liver histology, demonstrated by hematoxylin-eosin staining, and decreased the protein abundance of collagen I, the primary ECM component deposited in fibrotic liver. Examinations of TGF- $\beta$ signaling in rat fibrotic liver also yield consistent results with the in vitro experiments, confirming the molecular mechanisms by which curcumin inhibited hepatocyte EMT. These data could also support that hepatic EMT contributed to the pathogenesis of chronic liver disease and revealed that curcumin attenuation of liver fibrosis could be linked to the suppression of hepatic EMT. Several studies have demonstrated that a population of hepatic fibroblasts could be derived from mature hepatocytes in response to liver injury, suggesting that the EMT-derived hepatic myofibroblasts proliferate and upregulate their production of fibrillar collagens with a resultant increase in the deposition of fibrotic matrix. ${ }^{5,15}$ TGF- $\beta$-induced hepatocyte EMT and EMTinduced fibrosis could be attenuated by histone deacetylase inhibitor via epigenetic modulation of type I collagen. ${ }^{26}$ However, there were also data challenging the concept that hepatocytes in vivo acquire a mesenchymal phenotype through EMT to produce ECM components in liver fibrosis in mice. ${ }^{7}$ These divergent findings could be due to the failure to rigorously define EMT with specific and convincing markers. In current study, we examined vimentin, $\alpha$-SMA, fibronectin, and collagen synthesis as primary markers of EMT, because these features are ultimately most relevant to fibrosis. Our data could provide the evidence that EMT occurred in chronically injured liver in rats and indicate that strategies aimed at blocking TGF- $\beta$ signaling might be beneficial for reversal of hepatocyte EMT during liver fibrosis. It bears emphasis that interference with the TGF- $\beta / S$ mad pathway could be one mechanism underlying curcumin suppression of hepatocyte EMT and that curcumin may exert its potent antifibrotic effects through multiple mechanisms.

In summary, the current data demonstrated that curcumin could inhibit hepatocyte EMT in cultured LO2 cells and in experimental liver fibrosis in rats. These effects were associated with interference with TGF- $\beta /$ Smad signaling in hepatocytes. Our data identified a novel function for curcumin as a therapeutic agent for treatment of liver fibrosis.

\section{ACKNOWLEDGMENTS}

The financial support was from the National Natural Science Foundation of China $(81270514,31401210)$, the Youth Natural Science Foundation of Jiangsu Province (BK20140955), the Natural Science Research General Program of Jiangsu Higher Education Institutions (14KJB310011), the Youth Natural Science Foundation of Nanjing University of Chinese Medicine (13XZR20), the Project Funded by the Priority Academic Program Development of Jiangsu Higher Education Institutions (ysxk-2010), and the 2013 Program for Excellent Scientific and Technological Innovation Team of Jiangsu Higher Education.

\section{DISCLOSURE/CONFLICT OF INTEREST}

The authors declare no conflict of interest.

1. Kalluri $R$, Weinberg RA. The basics of epithelial-mesenchymal transition. J Clin Invest 2009;119:1420-1428.

2. Zeisberg M, Neilson EG. Biomarkers for epithelial-mesenchymal transitions. J Clin Invest 2009;119:1429-1437.

3. Acloque $\mathrm{H}$, Adams MS, Fishwick $\mathrm{K}$ et al. Epithelial-mesenchymal transitions: the importance of changing cell state in development and disease. J Clin Invest 2009;119:1438-1449.

4. Nitta T, Kim JS, Mohuczy D et al. Murine cirrhosis induces hepatocyte epithelial mesenchymal transition and alterations in survival signaling pathways. Hepatology 2008;48:909-919.

5. Zeisberg $M$, Yang $C$, Martino $M$ et al. Fibroblasts derive from hepatocytes in liver fibrosis via epithelial to mesenchymal transition. J Biol Chem 2007;282:23337-23347.

6. Copple BL. Hypoxia stimulates hepatocyte epithelial to mesenchymal transition by hypoxia-inducible factor and transforming growth factorbeta-dependent mechanisms. Liver Int 2010;30:669-682.

7. Taura K, Miura K, Iwaisako K et al. Hepatocytes do not undergo epithelial-mesenchymal transition in liver fibrosis in mice. Hepatology 2010;51:1027-1036.

8. Zavadil J, Bottinger EP. TGF-beta and epithelial-to-mesenchymal transitions. Oncogene 2005;24:5764-5774.

9. Ikushima H, Miyazono K. Biology of transforming growth factor-beta signaling. Curr Pharm Biotechnol 2011;12:2099-2107.

10. Fu Y, Zheng S, Lin J et al. Curcumin protects the rat liver from $\mathrm{CCl}_{4}$ caused injury and fibrogenesis by attenuating oxidative stress and suppressing inflammation. Mol Pharmacol 2008;73:399-409.

11. Lee $\mathrm{H}$, Bien $\mathrm{CM}$, Hughes $\mathrm{AL}$ et al. Cobalt chloride, a hypoxia-mimicking agent, targets sterol synthesis in the pathogenic fungus Cryptococcus neoformans. Mol Microbiol 2007;65:1018-1033.

12. Kim EH, Won JH, Hwang I et al. Cobalt chloride-induced hypoxia ameliorates NLRP3-mediated caspase-1 activation in mixed glial cultures. Immune Netw 2013;13:141-147.

13. Saxena S, Shukla D, Bansal A. Augmentation of aerobic respiration and mitochondrial biogenesis in skeletal muscle by hypoxia preconditioning with cobalt chloride. Toxicol Appl Pharmacol 2012;264: 324-334.

14. Lin Y, Dong C, Zhou BP. Epigenetic regulation of EMT: the Snail story. Curr Pharm Des 2014;20:1698-1705.

15. Kaimori A, Potter J, Kaimori JY et al. Transforming growth factor-beta1 induces an epithelial-to-mesenchymal transition state in mouse hepatocytes in vitro. J Biol Chem 2007;282:22089-22101.

16. Choi SS, Diehl AM. Epithelial-to-mesenchymal transitions in the liver. Hepatology 2009;50:2007-2013.

17. Barriga $\mathrm{EH}, \mathrm{Maxwell} \mathrm{PH}$, Reyes $\mathrm{AE}$ et al. The hypoxia factor Hif-1alpha controls neural crest chemotaxis and epithelial to mesenchymal transition. J Cell Biol 2013;201:759-776.

18. Higgins DF, Kimura K, Bernhardt WM et al. Hypoxia promotes fibrogenesis in vivo via HIF-1 stimulation of epithelial-to-mesenchymal transition. J Clin Invest 2007;117:3810-3820.

19. Diaz R, Kim JW, Hui JJ et al. Evidence for the epithelial to mesenchymal transition in biliary atresia fibrosis. Hum Pathol 2008;39: 102-115.

20. Marijon H, Dokmak S, Paradis V et al. Epithelial-to-mesenchymal transition and acquired resistance to sunitinib in a patient with hepatocellular carcinoma. J Hepatol 2011;54:1073-1078.

21. Zheng S, Chen A. Disruption of transforming growth factor-beta signaling by curcumin induces gene expression of peroxisome 
proliferator-activated receptor-gamma in rat hepatic stellate cells. Am J Physiol Gastrointest Liver Physiol 2007;292:G113-G123.

22. Sun $X D$, Liu $X E$, Huang DS. Curcumin reverses the epithelialmesenchymal transition of pancreatic cancer cells by inhibiting the Hedgehog signaling pathway. Oncol Rep 2013;29:2401-2407.

23. Chen WC, Lai YA, Lin YC et al. Curcumin suppresses doxorubicininduced epithelial-mesenchymal transition via the inhibition of TGFbeta and PI3K/AKT signaling pathways in triple-negative breast cancer cells. J Agric Food Chem 2013;61:11817-11824.
24. Brown KA, Pietenpol JA, Moses HL. A tale of two proteins: differential roles and regulation of Smad2 and Smad3 in TGF-beta signaling. J Cell Biochem 2007;101:9-33.

25. Zhang S, Sun WY, Wu JJ et al. TGF-beta signaling pathway as a pharmacological target in liver diseases. Pharmacol Res 2014;85:15-22.

26. Kaimori A, Potter JJ, Choti $M$ et al. Histone deacetylase inhibition suppresses the transforming growth factor beta1-induced epithelialto-mesenchymal transition in hepatocytes. Hepatology 2010;52: 1033-1045. 